Accepted refereed manuscript of:

Dimeo P (2016) The Myth of Clean Sport and its Unintended Consequences, Performance Enhancement and Health, 4 (3-4), pp. 103-110.

DOI: $\underline{10.1016 / j \cdot p e h .2016 .04 .001}$

(c) 2016, Elsevier. Licensed under the Creative Commons AttributionNonCommercial-NoDerivatives 4.0 International

http://creativecommons.org/licenses/by-nc-nd/4.0/ 


\section{The Myth of Clean Sport and its Unintended Consequences}

\section{Abstract}

Anti-doping has long been premised on the myth of clean sport, a consistent vision that has survived changes in the social and cultural environment. This article starts with a discussion of the meaning of clean sport focusing on the gap between this idealisation and practice. It then traces the historical emergence of this myth, briefly explaining its cultural foundations, and its influence on incompetition drug testing development in the 1960s. It will be argued that clean sport only made sense when the focus was on in-competition use of stimulants. The emergence of drugs such as steroids, used out of competitions, created a conflict between the reality of doping practices and the mythical past and future idealisation of sport as clean. Nonetheless anti-doping leaders maintained their public position that testing systems could defeat doping practices. Due to the continuity of ethical ideas, the construction of health fears, and public scandals, the World Anti-Doping Agency pressed on with, and was empowered by, the absolutist clean sport vision leading to the conceptually flawed, contradictory, draconian and problematic policy environment we face today.

\section{Introduction}

The myth of clean sport has been an idealistic feature of anti-doping discourses since the inter-war period, and subsequently underpinned the creation and implementation of a list of banned substances in the late 1960s. It has become a common sense narrative, taken for granted as the purpose of anti-doping, and related to the tendency to see sport in general as a beneficial social good. Coalter's (2007) discussion of the ways in which sport is idealised in public policy making as embodying a series of vague and presumed social benefits (i.e. health, community, urban regeneration, economic, and individual self-esteem) is helpful in understanding how and why anti- 
doping came to be supported by latent beliefs in the nature and role of sport in society. He writes that sport has a 'mythopoetic' status:

Mythopoetic concepts tends to be one whose demarcation criteria are not specific ... Such concepts are based on popular and idealistic ideas ... Such myths contain elements of truth, but elements which become reified and distorted and 'represent' rather than reflect reality, standing for supposed, but largely unexamined, impacts and processes. (p. 9)

The rhetoric of clean sport has become banal: accepted without question by the global sports community as a reflection of the true essence of sport. In this sense, anti-doping has mirrored the mythopoetic approach to sport as a whole to establish 'clean sport' narratives as both indicative of sport in its broadest sense and as justification for intensive regulations.

A brief scan of relevant organisations websites shows how this concept is prominent and easily reproduced. The World Anti-Doping Agency (WADA) uses 'clean sport' as a focal point for its efforts. For example, in April 2015 it released a statement encouraging whistleblowing:

The World Anti-Doping Agency (WADA) is encouraging supporters of clean sport worldwide to help protect the clean athlete by reporting information relating to doping. Clean sport proponents - including members of the public, media, anti-doping stakeholders and athletes - are encouraged to report doping via a new page on WADA's website. (WADA 2015)

We can see how anti-doping is linked to the mythopoetic sense of sport's values in the WADA's description of the 'spirit of sport' as 'the celebration of the human spirit, body and mind, and is reflected in values we find in and through sport' and so 'Doping is fundamentally contrary to the spirit of sport' $(2015$, p. 14).

Another example is that UK Anti-Doping regularly hosts an annual 'Clean Sport Forum' and uses the term to focus on athlete responsibility: 'All athletes in the UK are part of clean sport. It is the mission of UKAD to protect your right as an athlete to compete in clean sport.' (UK Anti-Doping 2015). 
Finally, from the United States Anti-Doping Agency (USADA), a clean sport campaign which promotes the claim that 'true athletes compete clean for many powerful and personal reasons'. From there, athletes and coaches are invited to 'take the pledge today to boldly declare why you compete clean'. Some of the suggested reasons are listed by USADA: 'family, health, integrity, love of sport, country, legacy' (USADA 2015).

While it is easy to find examples of the discursive strategies and meanings conveyed by the term, it is significantly more challenging to ascertain what it means. Assuming we confine an interpretation to the locus of anti-doping (i.e. not include other forms of cheating and corruption), a broadly stated definition might be that sport is free of drugs and other forms of artificial enhancements. As will be discussed, this was the vision of early anti-doping enthusiasts. This pertains towards a sense of the natural body which is not enhanced through any means except careful and dedicated training; a concept laden with class and ethnocentric bias, reflective of amateur ideologies in sports cultures (Gleaves and Llewellyn, 2014; Henne 2015).

In order to have practical meaning, the vision of clean sport needs some form of a structure, as no one would expect athletes to refrain from using all available drugs. The development of the list of banned substances in the 1960s aimed to delineate acceptable from unacceptable. Judgements would be made by a core group of Western, male, middle and upper class scientists and administrators who wanted to protect their own power base while utilising vague notions of the essence and ethics of sport (Dimeo 2007). However, the details were fraught with dilemmas. Athletes would be allowed use such drugs as paracetamol, birth control pill, supplemental vitamins and so on, that were accepted because they were used widely in society, relatively harmless and not performance enhancing. The powerful social elite did not trust athletes and their support staff to follow the rules independently, so created a testing system that could inform sports organisations whether or not athletes had contravened the regulations and used a banned substance or technique. Since an 'analytical finding' is almost always the only source of evidence, the pragmatic 
description of an athlete as clean can only really refer to whether or not they have been caught doping. As such, the concept is not an obvious as it may ostensibly appear to be, and is evidently an ideology rather than empirical fact.

This article traces the historical development of this vision and its influence on drug testing implementation in the 1960s. It will be argued at this juncture that the logic of in-competition testing for stimulants was actually quite reasonable as it focused on a single event and the possibility that an athlete boosted their short-term performance to win a podium place over a non-stimulant using athlete. Of course, such event-only testing did not show that sport was clean as athletes could easily use drugs during their training periods. The logic of clean sport however led inevitably to a ban on steroids once a test had been established, and in the absence of out-of-competition testing, athletes freely used steroids and clean sport was a fallacy.

Nonetheless, the clean sport message remained in place and, due to ethical positioning, health fears and public scandals, was simply reinforced by WADA from 2000 onwards. It is both backward and forward looking: providing an imagined and essentialised image of the past, alongside a model of progress for the future. It paints a picture of present-centred crisis, a loss of ethical direction, that needs resources, regulations and punishments in order to be recovered and the future to become a better place. Therefore, it is a strategy about power enhancement, indeed power over athletes and their entourage, that places control with centralised authorities who can impose their will over those defined as 'transgressors'.

Yet, the demands for clean sport have led to draconian, unfair and ineffective policies (Møller 2014; Goode 2015); one consequence of which is the historical and contemporary failure of anti-doping to deliver a clear distinction between the cheats and the innocent. It will be argued that the absolutist vision is unhelpful as it creates myth-based expectations that cannot be fulfilled. Instead, it is proposed that a more realistic sense of performance enhancement and sport, and fairer treatment of guilty and innocent athletes, should be considered for future policy initiatives. 


\section{Amateurism and naturalism: the original ideas behind clean sport}

As Gleaves and Llewellyn correctly point out, there has until recently been a lack of understanding the early $20^{\text {th }}$ century debates on drugs in sport. They correctly argue for a broader historical framing of the problem in contra-distinction to the various scholars who have taken the death of Danish cyclist Knud Enemark Jensen during the 1960 Olympic Games as the launching point for tracing the roots of anti-doping policy. They write:

bureaucratic concerns about doping not only predated the Second World War but were also framed by the IOC almost exclusively within the context of amateurism. As the IOC's regulatory framework governing conduct and eligibility, amateurism required athletes uphold certain moral standards. The Olympic amateur played the game for the game's sake, disavowed gambling and professionalism, and competed in a composed dignified manner fitting of a 'gentleman'. Anti-doping rhetoric, and later legislation, first emerged as part of the early twentieth-century push to defend amateurism against the perceived nefarious forces of gambling, commercialism, professionalism and totalitarianism that were supposedly overrunning amateur sport (2014, p. 840).

John Hoberman (1992) and Paul Dimeo (2007) show that this was a period of growing awareness of potential performance enhancing methods, partly legitimised by broader concerns over fatigue among workers and soldiers, and partly by scientific curiosity regarding the properties of stimulant and other drugs. By contrast, many in the upper echelons of world sport wanted to protect the reputation of sport as both a form of healthy physical exercise and a cultural space with specific ethical values. Amateurism played a large part in fomenting anxieties around drugs, which somehow smacked of an over-seriousness found normally in professional sports. While there is some evidence suggesting that sports leaders took a passive stance towards drug use in cycling, others focused their 
anti-doping concerns on 'purer' environments such as the Olympic Games. The International Olympic Committee (IOC) President Henri de Baillet-Latour provided a useful illustration of the perceived inter-relationship of values and the threat of doping in 1937: 'amateur sport is meant to improve the soul and the body therefore no stone must be left unturned as long as the use of doping has not been stamped out' (1937, no page, cited in Gleaves and Llewellyn 2014, p, 847).

Neither the IOC nor any sports organisation had the weaponry to start the fight against doping. However, the International Amateur Athletics Federation (IAAF) in 1928 and the IOC in 1938 made official statements prohibiting artificial methods of performance enhancement. The IAAF proposed that doping should be prohibited and defined it as 'the use of any stimulant not normally employed to increase the power of action in athletic competition above the average' (IAAF 1928, p. 43, cited in Gleaves and Llewellyn 2014, p, 846).

As lan Ritchie (2015) points out: 'the values of the people that created the first anti-doping statements of principle and sanctioning rules, alongside the general social environment within which those principles and rules were created, are instructive in terms of thinking about the issue today' (p. 21). Quite whether there is a linear thread between the ideas and leaders of anti-doping between the 1920 s and the firming up of policy in the 1960s is open to debate. Not least because political and cultural influences changed over time and place. However, Ritchie does highlight the importance of trying to understanding continuities and discontinuities. He goes on: 'many of the contradictions and continued problems within the anti-doping movement today were created because of the assumptions built into the original prohibitions' (2105, p. 21; see also Hunt et al. 2012). The notion of clean is one such continuity, a theme that has proved enduring and persistent despite many challenges.

Even the early post-war sports leaders such as IOC President Avery Brundage were keenly aware that the financial and human resources to undertake extensive drug testing were not available. He insisted in 1968 that the IOC could not undertake this task and called upon the international sports 
federations to do so (IOC 1968). The British anti-doping campaigner Sir Arthur Gold, who was British Amateur Athletic Board secretary, President of the European Athletic Association and Chairman of the Commonwealth Games Council for England, later said that many of his colleagues saw antidoping as an unwinnable war, he said '[anti-doping] was raised at the IAAF Conference or World Congress in Mexico in 1968 and the idea that one could do anything about it was laughed out of court' $(1985$, p. 3).

The other form of resistance to anti-doping extremism came in the form of contextualisation, with some commentators pointing out how conceptually challenging it would be to differentiate doping from other forms of performance enhancement. During a debate in British sport, organised in London by the British Association for Sports Medicine, a doctor, M. Hollyhock (1967), argued that drugs such as amphetamines and steroids could be used safely under medical supervision, and that the use of drugs 'is not more unfair than the fact that one athlete will have a good coach and excellent training facilities whereas another does not' (p. 126). This is one issue that has continued to be discussed by sports scholars, even if anti-doping policy leaders seem to assume that (some) drugs were to be defined and controlled as an unequivocally illegitimate form of performance enhancement.

Regardless of these internal struggles, anti-doping campaigners were positioning their case in strong terms. The myth of clean sport and the call for more resources and optimism was articulated in relation to testing cyclists at the 1967 Pan-American Games, when the authors of the official report, the Canadian doctor M. F. Innes and pharmacologist John Steele, wrote: 'All drugs at all dose levels should be banned... There is an urgent need for rapid, precise laboratory methods for carrying out drug testing in athletes. Funds are required to support research programmes in this area ... It is felt that with a cooperative effort on the part of the cycling officials, coaches, trainers and the medical profession, the drug problem in cycling could be eradicated in less than a generation' (1968, p. 279). As Dimeo (2007) shows, the application of testing procedures in cycling, football and the Olympics 
between 1965 and 1968 was presented as if the solutions were appropriate and needed to be further supported.

The scientists who pioneered anti-doping established a logic which remains with us today: if society wants clean sport then we need the resources to achieve it; and we can do so by promoting research into testing and increasing the extent of testing. They became highly influential in their bid to identify a problem and propose rational solutions, and in doing so set a framework from which there was no return. As Henne (2015) explains, these decades saw the development of an approach based on the interaction of notions of 'purity', ethics, social power, and with science as the proposed solution:

Innovations in anti- doping technologies reveal an enduring commitment to diagnosing impure subjects. The rational veneer of techno-science can convince observers that regulatory findings provide proof of deviance and immorality, even though such innovations are simply creating new categories and distinctions that become classified as evidence of doping. Through a series of a priori claims and scientific tactics, the regime presents bodily purity as the natural condition of athletes despite the impossibility of bodily purity. Categories of doped and pure bodies - or "dirty" and "clean" to use anti-doping rhetoricare imagined as facts. In sum, the science of testing helps us believe that purity is a reasonable expectation to have of athlete citizens. The myths of bodily purity and a level playing field, combined with the scientific and legal tools used to maintain them, feature prominently in the maintenance of athlete citizenship. (p. 21)

\section{Steroids, the impossibility of clean sport and the façade of progress}

Influential leaders continued to promote the claim that testing could lead to clean sport. In 1971, Prince Alexandre de Merode, the Chair of the IOC Medical Commission, spoke to the IOC and said 
that new drugs tests ' will have a positive effect in the immediate decrease and future elimination of the danger of doping in modern sport' (cited in Hunt 2011, p. 40). The very idea that drug controls could prevent the misuse of stimulants was somewhat naïve. However, the arrival and dissemination of anabolic steroids created an unmanageable situation. Hunt explains that prior to the 1972 Olympic Games, the IOC President Avery Brundage had challenged de Merode on athletes' new drug of choice, steroids. De Merode replied to say there was not enough research to establish a test for those drugs, and the IOC Executive Board limited the Medical Commission's authority to the period immediately preceding and following the Games (Hunt 2011, p. 41). Here was a tacit acceptance that steroids use away from the event could not be controlled due to the lack of testing mechanisms and the lack of a remit for the IOC. The Medical Commission took a decision that this class of drugs should not be banned until a test was discovered (which occurred in 1975). In practice, this meant that steroids were allowed: a direct contradiction of the clean sport vision. It also meant that antidoping's parameters had to shift if any form of control was to be implemented. No longer was doping restricted to in-competition behaviours, and no longer was the 'benefit' of doping confined to a short burst of energy at a key moment within the competitive framework. The game had changed. Around the same time, emerging professionalism in Olympic sports, and the apparent need for anti-doping in professional sports, meant that amateurism could no longer provide the moral justification for clean sport.

However, and in spite of the growing awareness of drugs being used in training periods, the clean message could not be retracted as that would mean revisiting the essentialised perception of sport as a social good, as healthy, and as ethical. A challenge to anti-doping would also be a challenged to the post-amateurism powerful social groups that still controlled world sport. Leaders such as de Merode were forced to keep up an image that doping was not really extensive, and that the science of testing was on the verge of vanquishing the problem. The illusion of control was presented, a public relations exercise that bore no reflection of reality. As Taylor (1991) argues, these positions curtailed open discussions of steroid use, leading to flawed understandings of their properties, and 
risky self-experimentation among athletes. At national level, some sports organisations felt they had no choice but to allow their athletes to dope. This was a highly ambiguous period, wherein the façade of progress and the myth of clean sport, combined with the failings of the policy and testing systems, to facilitate a secretive but large world of doping and consequent potential health risks.

By the early 1970s the use of steroids was extensive in Olympic and professional sports but de Merode ploughed the same furrow. In the aftermath of the first steroids testing introduced in the Olympics in 1976, he wrote that: 'The analytical testing of the non-medical use of drugs at the Olympic Games in Montreal marked a certain number of steps forward in the long and difficult fight against doping' (1979, p. 10). He went on to argue that the 'methods of detection continue to evolve at a more rapid pace than the discovery and launching of new products ... the testing possibilities placed at the disposal of sports authorities are no longer outpaced by the attempts to circumvent them' (1979, p.10). The claims that anti-doping was a success continued. Dr Michel Bertrand, who helped run the doping controls at the 1980 Winter Games in Lake Placid, New York, said in 1979 that 'The equipment acts with the precision of radar. We are confident it will be a deterrent, because athletes who think they can risk trying us will be making a mistake' (cited in Cady 1979, p. 64).

Reflecting on this time period, lan Ritchie (2015) recently wrote that:

by the early 1970s, amateur ideals were formally abandoned and relevant rules and restrictions were removed from the Charter. But drug use was one aspect of sport that could be controlled, or at least certain members of the IOC perceived it could, and so rules were put in place and procedures for detection and punishment were implemented, and these continue to this day, albeit with greater scientific sophistication and the commitment of greater money and infrastructural resources. But because 'ethics' per se was never considered - because the $\mathrm{IOC}$ was trying to 'turn back the clock' and preserve images of Olympic purity in light of dramatic and embarrassing cases - the anti-doping movement was 
faced with a series of contradictions in its policies that, arguably, continue to the present day. (p. 28)

It could be argued that the IOC and other international federations lacked the financial resources and support from important political stakeholders. They had no jurisdiction beyond the scope of the Games and no ability to investigate national sporting systems. By the time of the 1972 Olympics, East Germany, the USSR, West Germany and so a lesser extent the USA, had organised doping methods in order to ensure competitive parity at a time when the Olympics had powerful ideological significance (Hunt and Dimeo 2014). While members of the IOC might have wished to preserve some historically grounded idealism around amateur values and anti-doping, the reality was at the other end of the spectrum.

It remains unclear why the IOC stuck with the idealism of clean sport when its leaders might have taken a more pragmatic approach based rationally upon the fact that this was an unwinnable war. Some scholars have argued that the IOC wanted to protect the image of sport, trying to avoid public relations scandals and bad press. That may account for de Merode's insistence that, for example, the 1980 Games in Moscow were 'clean', when subsequent research would prove this to be naïve as the German scientist Professor Manfred Donike found high levels of doping drugs when he analysed samples in 1982 (Hunt 2011). In between those moments, the scandal of the Pan-American Games in Caracas in 1983 highlighted the extent to which steroids had become commonplace in international sports. Perhaps, as Henne (2015) argues, the cultural underpinnings of anti-doping can be found in understanding the power structure of sport. She argues that first-world, middle class values were expressed in amateurism. However, they continued to be imposed on professional sport through accusations of cheating levelled at 'others':

Drug testing, initially intended to catch unnatural athletes using doping agents, continues to secure a particular set of privileged first-world values, as evidenced by its longstanding preoccupation with professional and Eastern Bloc athletes. With suspicion of athletes 
institutionalized through the biomedicalized tools, the targets of anti-doping regulation have come to encompass a broader range of bodily impurities. The bodies most publically condemned for transgressing the terms of athlete citizenship, however, are those already seen as suspect to a Western gaze, particularly non-Western bodies and bodies of colour. ( $p$. 55)

The 1980s became a decade of scandals, not least the Ben Johnson affair, because the IOC claimed to be able to control a culture that was in fact uncontrollable, and they had set a high bar of moral expectations that athletes could not live up to in the modern professional and politicised world of sport. Anti-doping was not really just about protecting amateur sports values, those had gone already. It was not about short-term impactful cheating through stimulant use. We need to take a wider lens to understand the authority invested in the clean sport vision, based on a nostalgic view of sport and a hope for a better future, and allied with a clear set of social anxieties about the fear of un-natural bodies and fears of death. Central to both are fundamental ideas about the relationship of science and humanity. The consequences are a highly complex, draconian, myth-based, ineffective system that makes victims of the innocent and the guilty.

\section{Anti-Doping Narratives: Fear, Morality, Clean Sport and the Essence of Sport}

Given the complexities of world sport and the ineffectiveness of anti-doping, why did influential scientists and policy leaders continue to pursue the path of clean sport?

One potential explanation is that they had a deep-rooted sense that drugs contravened something essential and vital about sport. De Baillet-Latour had a strong feeling that doping undermined the improvements to 'soul and the body' that amateur sport provided. Sir Arthur Porritt, who was asked by Avery Brundage to lead the IOC's fight against doping, had many strong words to say on the matter. He wrote in 1965 that doping is 'an evil - morally wrong, physically dangerous, socially 
degenerate and legally indefensible'. He argued that drug users showed 'weakness of character' (1965, p. 166). He went on to imply that modern life was to blame: '[doping is] a temptation in this fast moving dynamic and somewhat amoral world in which we live today' (1965, p. 167). One of the most influential anti-doping scientists of the time, Professor Ludwig Prokop, wrote that anti-doping efforts 'should result in the effective protection against the immoral act of doping. Thus we shall be able to continue to keep the ideal of sports pure, for the welfare of all mankind' (1966, p. 269). A similar idea was expressed by the anti-doping pioneer Antonio Venerando, who argued that drug controls are needed 'to avoid the risk of further damage and unethical victories won by fraud. Young people will then return to sport with unblemished aims, competing by fair means and restoring to sport its primary function as a means of preparation for life itself'. (1964, p. 53)

The essence of sport was imagined to be focused upon fairness and health. In 1969, the American journalist Bil Gilbert wrote that drug use could undermine the 'tradition and structure of sport itself' (1969; cited in Hunt 2011, p. 37). This sentiment was echoed by Lord Killanin, IOC President from 1972-1980 who saw doping as 'the most obnoxious aspect of sport' that could lead to the 'destruction of competition as we know it' (1983, p.155). Similarly, a prominent British sports administrator Sir Arthur Gold, said, 'sport is about health and honesty, and drug abuse is unhealthy and dishonest, the very negation of sport ... If sport is to mean anything at all it must be kept free of drugs'. (1985, p. 7)

During the pre-steroids era of drug testing, perhaps such ideas and the possibility of clean sport made more sense. If the only drugs of concern were stimulants that provided a short-term boost of energy and speed, during competition, then the cheating aspect was comprehensible. If those could be tested for straight after an event then the authorities could determine if a specific athlete had sought to gain this form of artificial advantage. In this sense, testing might have been successful to ensure a certain race had not been won by a cheating athlete. No-one could say for sure if all 
athletes were clean, but at least they could reassure the public that no athlete lost a medal due to their competitor's use of stimulants. This was a more realistic model of anti-doping.

However, central to the history of anti-doping, and to understanding contemporary dilemmas and unintended consequences, is that fact that the connection made in the 1960s between the moral purpose of sport, the essence nature of sport, and the use of drugs, remained a powerful ideological tool for continuing and promoting anti-doping through the channels of media, academia, education and policy regulations. Throughout the 1980s, the various scandals promoted reiterations of the moral/clean sport message. In response to the Ben Johnson scandal, the eminent British track and field coach Ron Pickering said in the immediate aftermath: 'Good should never give way to evil, and this is evil that is being exposed' (BBC 2005). More broadly, Henne notes, 'Johnson's condemnation and punishment, including the Dubin Inquiry launched by the Canadian government in the aftermath of his positive test, aimed to distance the Olympics and the nation from his polluted body. This, an elaborate melodrama, not only labeled Johnson deviant but, and perhaps more importantly, preserved the appearance of national and Olympic purity'. (Henne 2015, p. 50)

The major international scandal of the East German doping system, revealed after the demise of the country, also served to reinforce the notion that doping was inherently connected to immorality. One such example comes from the New York Times, which describes the initial revelations and admissions from coaches involved with East German athletes. The newspaper quoted a conversation in which an American swimming coach Sherm Chavoor confronted his East German counterpart about the health risks of doping; the latter replied 'But bodies are expendable'. (cited in Janofsky, 1991)

During this period of the late 1970s to the late 1980 s, the sense that unrestricted use of powerful muscle-building drugs challenges the naturalness of the human body had not disappeared. Lord Killanin wrote in 1983 that 'The Olympic ideal is to create the complete person - not an artificial one 
... through the efforts of certain doctors, the body is being more and more tampered with to its own detriment'. (1983, p. 117)

However a second, and more prominent, set of fears were expressed in health-related anxieties that often had the stark message that abuse of drugs like steroids, human growth hormone and EPO, could be fatal. Obvious examples include the Goldman and Klatz book in 1984 called Death in the Locker Room: Steroids and Sports. Public policy was being informed by such fears, illustrated by the numerous examples cited by Senator Joe Biden in his report that led to the US Government's Steroid Trafficking Act of 1990. Using case studies and citing scientific literature, he claimed 'the evidence is clear: steroids are dangerous drugs that can permanently disfigure young users - and, in some cases, can take young lives ... [and] can cause severe psychological disorders'. (1989, p. 103)

John Hoberman's 1992 classic Mortal Engines: The Science of Performance and the Dehumanization of Sport starts with the gory details of the tragic death of Birgit Dressel. Hoberman describes her symptoms: 'terrible pain ... fingernails turning blue and a white crust had formed on her lips ... [the] neurosurgeon began to suspect she had been poisoned'; more than 'two dozen specialists' fail to prevent her death $(1992$, p. 1). The autopsy did not reveal that doping had caused this outcome. However, Hoberman details that many people in West German sport 'assumed that her death had resulted from her use of the vast array of drugs and other fortifying substances police found in her living quarters'. She had been injected over 400 times by a sports doctors with 'dozens of substances, including proteins known to be immunologically hazardous ... [and] an anabolic steroid', summarised as 'the fatal chemistry of her death'. (1992, p. 2)

The aftermath of the East Germany revelations during the 1990s resulted in some influential findings by sports scientists and health researchers. Franke and Berendonk's (1997) highly cited paper listed the documented side-effects of steroid abuse as wide-ranging: muscle tightness, body weight increase, muscle cramps, irregular menstruation (including amenorrhea), acne and hirsutism, alteration of libido (and sexual potency and fertility), edema, diarrhoea and constipation, liver 
damage. The vast majority of these were related to the first four on that list. They proceeded to list side-effects reported by Stasi collaborators who were spying on athletes: 3 deaths, gynecomastopathy, severe liver damage, excessive hirsutism, acne, folliculitis, amenorrhea, polycystic ovarian syndrome, deepening of voice, nymphomania, loss of libido (only in males), and arrest of body growth (in adolescents). (p. 1273)

The full details of the health harms would be repeated and reinforced later by scholars and journalists, thus confirming the anti-doping position that clean sport is necessary. Various other global news stories of the 1990s would support the need for tougher regulation. The dissemination of the false claim that over 20 young cyclists had died of EPO poisoning in the early 1990s added weight to the anti-doping discourse.

The 1998 Festina scandal in cycling which occurred during the Tour de France and has been welldocumented. It demonstrated the extent of doping, and the complicity of team managers. The open secret of cycling's doping culture was (albeit slowly) starting to unfold. Despite the reality of sport being far from clean, ever since the steroid era began in the 1960s, paradoxically the message of clean sport was empowered by scandal after scandal. Suspicions of Chinese sport, and the calls for non-IOC leadership led eventually to the creation of WADA (Hanstad et al 2008). Every opportunity was taken to reinforce the claims of physical and moral harms caused by doping, and thus the need for clean sport.

So perhaps it is not surprise that the period of the 1990s, which would end with the formation of the WADA, is one in which the idealism and necessity of clean sport was regularly promoted by sports leaders. The Lausanne Declaration on Doping in Sport, adopted by the World Conference on Doping in Doping in February 1999 begin: 'Considering that doping practices contravene sport and medical ethics ... and concerned by the threat that doping poses to the health of athletes and youth in general'. (p. 3) 
In the aftermath of that conference, the organisers produced a summary of the working groups' discussions on how best to improve anti-doping measures. Once again, we see a powerful belief in moral purpose: '[Doping] is contrary to sports and medical ethics [and] the spirit of fair play ... The ideology of sporting excellence ... must not obscure the vital importance of moral, social and professional excellence'. (Anon, 1999, p. 15) The political environment has been examined elsewhere (Hanstad et al 2008), but what concerns the theme of this article is the lack of critical reflection on the idea that doping sits in contradistinction to the essence of sport. Arguably, WADA was established and legitimised by the need for a quick and powerful response to the scandals and health fears that had developed in the preceding decade. On the basis of that remit, it created a series of drastic and draconian solutions, alongside a practically compulsory global compliance strategy. Rather than allow each sport or country to address its own problems, the policy landscape was revolutionised with the aim of increasing testing, enforcing meaningful sanctions, harmonization and standardization. By not re-examining the basis of anti-doping, WADA have simply reproduced the myth of clean sport, a continuity across historical time periods that utilises the essentialised and mythical ideas that sport should be natural, fair and healthy, to create a more intensive, more powerful, surveillance and sanction based system.

\section{Clean Sport as Ideology and Practice}

There remains some problems over the myth of clean sport and how that informs policy and practice through various intended and unintended consequences. Larry Bowers, the Chief Science Officer of the United States Anti-Doping Agency, wrote in 2014, that 'Competition, in its true sense, deserves a playing field devoid of drugs' (p. 1279). In doing so, Bowers reflects one strand of a discourse that has become a prevailing norm. This norm leads to a policy system designed to evoke 'punishment as a form of condemning polluted bodies and distinguishing them from so-called pure ones' (Henne 
2015, p. 53). The policy gives those in power the tools to decide who needs to be punished. But there are unintended consequences masked by the ideological potency of clean sport.

An illustration of the cracks in the system relates to the use of medically necessary testosterone. In 2013, a 64 year old amateur and recreational hammer thrower from Oklahoma, Roger Wenzel, was tested positive for exogenous testosterone and banned for 2 years. He had a medical prescription for this drug to treat Parkinson's disease, had tried to gain advice from the relevant authorities (in other words, was honest), and could prove than even with the supplemental medicinal use his testosterone levels were still lower than the average man his age. A two year ban might fit with the image of clean sport, but serves no purpose other than to unfairly punish and stigmatize an innocent man and exclude him from healthy, sociable sports participation (Carlson 2013). More tragically, Roger Wenzel died of cancer before the end of his sanction - going to his death bed labelled a doper.

Wenzel's case bears similarities to those of Sloan Teeple and Jeff Hammond, though the latter made an informed choice to remove himself from sport after having a Therapeutic Use Exemption request denied (Henning and Dimeo 2014, 2015). Other athletes refused to request permission for medically required testosterone. The marathon runner Ryan Hall was diagnosed with low testosterone leading to bouts of fatigue that undermine his training schedule and competitive opportunities. Yet, he has accepted the policies, saying: 'There isn't anything that I can legally do to change that and even if I were to get a TUE (therapeutic use exemption) for testosterone, I still wouldn't take a synthetic version because then the body stops producing testosterone naturally. I also feel like taking synthetic testosterone, even with a TUE, crosses a moral line that I am not willing to cross' (cited in Fraioli 2015). The English professional cyclist who competed in the late 1980s and early 1990s, Chris Boardman, who has suffered from osteopenia, the precursor to osteoporosis since 1998 due to untreated hypogonadism which was identified in 1997. He had approached the UCI to be allowed to use testosterone but this application was turned down after the Festina scandal. He said: 'I 
presented two dossiers from individual specialists and a bone scan. They said it was no problem. I got it organised and they turned me down because of what had been going on [Festina]. They said that if I wanted the treatment I would have to stop cycling' (cited in Fotheringham 2000). As with Hall, Boardman's performances suffered, and ever since he had had to continue pre-emptive lifestyle changes to avoid recurrence of his illness. (Anstead 2009)

Larry Bower's presentation of the reasons for stringent anti-doping highlights the contradictions between the desire for clean sport and the practice of anti-doping. He argues that the 'objective of an anti-doping program' is 'to deter the athlete from making the decision to use a performanceenhancing drug or method ... the decision to cheat' (2014, p. 1279). He goes on to argue, in ways reminiscent of the 1960s paternalistic pioneers, that those who make the decision to dope do so because their 'moral inhibitions are weak'. And that, 'we would truly be dopes to fail clean athletes and lose the true value of sport' (p. 1279). This paradigmatic position was outlined a few years previously by the influential first President of WADA, Dick Pound (2006), who wrote that, 'The people who endorse the [anti-doping] rules have a positive view of what sport should be. They believe in the concept of the 'spirit of sport', which is defined as 'the celebration of the human spirit, body and mind'. (p. 39)

The anti-doping discourse equates doping with cheating, artificiality and immorality, and thus reemphasizes the desire for clean sport. The complexities and lack of reality of clean sport is not acknowledged. Cases such as the medically required testosterone serve to illustrate the profound negative human cost of this uncompromising vision of the past and future, and absolutist approach to policy. However, these are only one type of cases where there is lack of intention to dope and to cheat. For example, the use of tainted supplements (de Hons and Coumans 2007). These though are treated the same of case of deliberate cheating, not least due to the suspicions held that athletes cannot be trusted and thus any potential loopholes needs to be closed. 
A further criticism is that the performance enhancing effect of the drugs for which athletes get sanctioned are hard to fathom. A clear case here is the use of cannabis, which is actually likely to inhibit performance. However, even using the supposedly more serious drugs like EPO and steroids do not give a linear boost in performance like the in-competition use of stimulants might. The effect of EPO is similar to training at altitude or using a hypoxic training method. The effect of steroids depends upon training regimes and physiological response rates, as well as dosages. Many other drugs that are banned, such as diuretics, have no effect on performance. There is also the thorny issue of false positives, that can lead to innocent athletes having their careers ruined.

There are many other criticisms of WADA's policies that have been identified elsewhere (see Møller et al 2015). These include the intensive and intrusive methods of surveillance, the legal dilemmas around grey area cases, and the lack of pre-emptive education of athletes and coaches. Philosophers have pointed out that many of the underpinning ideas behind anti-doping policy are in fact myths that are easily accepted and re-circulated because they fit with the purpose and ideological framework. Yet, WADA and its stakeholders continue pursuing a path, aiming towards clean sport, in which athletes are increasingly tested, sanctions are tougher, and scientists receive millions of dollars to research sophisticated methods of analytical detection.

Perhaps most damning, anti-doping organisations have failed to deliver on their core purpose: to reassure the watching public that doping cheats do not win races. The number of athletes testing positive globally is around $2 \%$ of all tests. If we remove recreational and unintentional cases (though the exact number is unknown), then this figure would be even lower. Yet, social science research shows that over $10 \%$ of surveyed athletes admit to doping (varies according to sport and country, with higher levels among second tier levels) (Pitsch and Emrich 2012; Dimeo and Taylor 2013; de Hon et al 2015). Of those athletes who are sanctioned, many have not been within the upper echelons of the competitive environment. If they are in team sports, it is hard to work out the benefits of their doping upon the matches they played in. In other words, the system does not work 
to catch dopers consistently, and those who are caught are often not guilty of having deliberately cheated and taken a podium place over a clean athlete. Even though WADA have provided a rigorous, well-resourced, inter-connected policy environment, and built up a lot of support from Governments and the media, they have not brought us much closer to the vision of clean sport.

\section{Conclusion}

The power of the clean sport myth, while based on limited understandings, half-truths and a handful of outright lies, does remain the single vision of WADA. As Henne (2015) shows: 'the regime presents bodily purity as the natural condition of athletes despite the impossibility of bodily purity' (p. 21). It can also be said that the regime is self-perpetuating: any time a major scandal occurs the proposed solution is tougher policies, more testing and more funding for the imagined scientific solutions. It has been challenging for academic researchers to influence policy makers, as any alternative vision is treated with suspicion - clean sport has to be part of the culture of international sport, regardless of the technologies and commercialisation revolutions of the past 50 years. This article has briefly traced how an idea that might have been sensible in the 1960s took root due to powerful social elites and the manufacture of public expectations. It created a vision for the future with historical sentiments, something to strive for, but also an idea to promote the interests and power base of anti-doping leaders. In sociological terms, it separated the virtuous 'self' from the dirty 'other'. The cultural force of purity and institutionalisation of suspicion was supported by the science of testing.

Arguably change is required in order to redress a number of problems. Firstly, there is an unrealistic ideological framework around performance enhancement and sport. This creates dilemmas: it is acceptable to train at altitude but not use EPO; athletes from wealthy countries and/or with good genetic inheritance are at a long-term advantage over others; athletes want success more than fairness or purity. Secondly, there should be fairer treatment of guilty and innocent athletes. At 
present, those caught doping are stigmatized in ways that are hard to justify and find few comparisons in other public arenas of modern life. They are not offered rehabilitation or counselling, their (only) life skills are no longer useful, and all their career achievements are over-shadowed by the doping allegation. This has led to instances of depression and (attempted) suicides. John Hoberman (2013) has provided two examples: 19 year old Polish cyclist Kacper Szczepaniak, who attempted to commit suicide after he was provisionally suspended for EPO use in 2010; Spanish cyclist Alberto Léon who killed himself in 2011 and being implicated in two major doping cases. Although no systematic research has been conducted, there are other cases, such as that of Jonathan Breyne, who attempted suicide in reaction to being abused on-line after a positive test for clenbuterol, that highlight the struggles faced by sanctioned athletes (Cycling News 2014). Discussing the trauma of dealing with a doping ban, Hoberman (2013) contends: 'Psychiatric emergencies of this kind demonstrate a need for the psychotherapeutic repair of some people who, undeterred by the anti-doping education to which they were exposed, cannot manage the emotional consequences of exposure and doping notoriety' (p. 141). Of course, it is not just those who deliberately cheat who struggle with emotional recovery: many inadvertent cases lead to stigmatization, bans, reduced income, and accusations with the public, other athletes and journalists.

Innocent athletes need the chance to have their cases considered in a just process where the burden of proof, intent and consequential outcome (i.e. did they win a race due to doping) should lie with the prosecution. Those who genuinely need TUEs should have the chance to make their case known to authorities without fear of reprisal. The current system of strict liability is designed to avoid debates over intention, motivation and performance benefits. Arguably, anti-doping requires strict liability to prevent excuse-making by real cheats. However, the rigour of the current approach means that athletes can be punished in circumstances where breaking the rules is not the same as having cheated. 
The myth of clean sport remains firmly in place: to dissuade and deter, to justify surveillance and suspicions, to gloss over criticisms of how WADA and its stakeholders operate. Yet it has not made sense since the 1960s. Supporters will claim that sport cannot afford to lose its grip on the virtues and values that can be promoted for the good of society as a whole. Others question whether the rules are in place for the right reasons, and whether they are fairly implemented. We have reached an impasse that can only be resolved by recognising that athletes are human beings that deserve compassion, respect and basic dignity, and by creating the opportunities for closer dialogue between anti-doping proselytizers and their critics.

\section{Reference List}

Anon (1999). Doping: Reflections of the Working Groups. Olympic Review, Feb-March: pp.15-16.

Anstead, M. (2009). Chris Boardman: I had to give up cycling at 32 because I had the bones of an old woman. Daily Mail. 15 November. http://www.dailymail.co.uk/health/diets/article-1227777/CHRISBOARDMAN-I-cycling-32-I-bones-old-woman.html. Accessed 11 January 2016.

BBC (2005). TV documentary. Reputations: Ben Johnson. 15 June.

Biden, J. (1989). Report: The Steroid Trafficking Act of 1990, US Senate, August 2.

Bowers, L. (2014). The Quest for Clean Competition in Sports: Deterrence and the Role of Detection. Clinical Chemistry. 60: 1279-1281.

Cady, S. (1979). Drug testers stiffen Olympic procedures. New York Times. December 7. Section B12.

Carlson, J. (2013). Life-saving meds cheat Roger Wenzel out of competing. News Oklahoma. March 4.

Coalter, F. (2007). A Wider Social Role for Sport: Who's Keeping the Score, London and New York: Routledge. 
Cycling News (2014). Breyne says internet forum comments drove him to suicide attempt. 3 January. http://www.cyclingnews.com/news/breyne-says-internet-forum-comments-drove-him-to-suicideattempt/. Accessed on 23. 3. 2016

de Baillet-Latour, H. (probably 1937). Essay on Amateurism.Box 44, Folder titled 'Baillet-Latour Letters', Brundage Archives. Lausanne: International Olympic Committee Library.

de Hon, O. and Coumans, B. (2007). The continuing story of nutritional supplements and doping infractions. British Journal of Sports Medicine. 41:800-805.

de Hon, O., Kuipers, H. and van Bottenburg, M. (2015). Prevalence of Doping Use in Elite Sports: A Review of Numbers and Methods. Sports Medicine. 45: 57-69.

de Merode, A. (1979). Doping Tests at the Olympic Games in 1976. Olympic Review, January, 135: $10-16$.

Dimeo, P. (2007). A History of Drug Use in Sport, 1876-1976: Beyond Good and Evil. New York and London: Routledge.

Dimeo, P. and Taylor, J. (2013). Monitoring drug use in sport: The contrast between official statistics and other evidence. Drugs: Education, Prevention and Policy. 20: 40-47.

Fotheringham, W. (2000) Boardman quitting to take drugs. Guardian, 12 October. http://www.theguardian.com/sport/story/0,3604,380917,00.html. Accessed 10 January 2016. Franke W. and Berendonk, B. (1997). Hormonal doping and androgenization of athletes: a secret program of the German Democratic Republic government. Clinical Chemistry. 43:1262-1279. Fraioli, M. (2015). Ryan Hall on His Recent Struggles, His Running Future and His Growing Family. October 6. http://running.competitor.com/2015/10/features/qa-ryan-hall-on-his-recent-struggleshis-running-future-and-his-growing-family 136951. Accessed 3.11.15. 
Gilbert, B. (1969). Drugs in Sport: Problems in a Turned On World. Sports Illustrated. June 23.

Gleaves, J. and Llewellyn, M. (2014). Sport, Drugs and Amateurism: Tracing the Real Cultural Origins of Anti-Doping Rules in International Sport. The International Journal of the History of Sport, 31: 839853

Gold, A. (1985). International Policy and Philosophy of Drug Control in Sport. Speech to Drugs Abuse in Sport: symposium for governing bodies conference. London: Sports Council, 27 March 1985

Goode, E. (2015). Is concern about sports doping a moral panic?. In Møller, V., Waddington, I. and Hoberman, J. (eds) Routledge Handbook of Drugs and Sport, London and New York: Routledge.

Hanstad, D.V., Smith, A. and Waddington, I. (2008). The Establishment of the World Anti-Doping Agency: A Study of the Management of Organizational Change and Unplanned Outcomes. International Review for the Sociology of Sport. 43: 227-249

Henne, K. (2015). Testing for Athlete Citizenship: regulating doping and sex in sport. Brunswick, N. J.: Rutgers Press

Henning. A. and Dimeo, P. (2015). Questions of fairness and anti-doping in US cycling: the contrasting experiences of professionals and amateurs. Drugs: Education, Prevention and Policy. 22: 400-409.

Henning, A. and Dimeo, P. (2014) The complexities of anti-doping violations: A case study of sanctioned cases in all performance levels of USA cycling. Performance Enhancement \& Health 3: 159-166.

Hoberman, J. (1992). Mortal Engines: The Science of Performance and the Dehumanization of Sport. New York: Free Press.

Hoberman, J. How much do we (really) know about anti-doping education?. Performance Enhancement and Health. 2: 137-143. 
Hollyhock, M. (1969). The Application of Drugs to Modify Human Performance. British Journal of Sports Medicine, 4: 119-27.

Hunt, T. (2011) Drug Games: The International Olympic Committee and the Politics of Doping, 19602008, Austin: University of Texas Press.

Hunt, T. and Dimeo, P. (2014). Doping and the Health of Athletes during the Cold War: A Comparative Analysis of the Two Sides of the Iron Curtain. International Journal for the History of Sport, 31: 2230-2244.

Hunt, T., Dimeo, P. and Jedlicka, S. (2012). The historical roots of today's problems: A critical appraisal of international anti-doping movement. Performance Enhancement and Health, 1: 55-60. Innes, M. F. and Steele, J. (1968). Anti-Dope Controls at the $5^{\text {th }}$ Pan-American Games. Report on the Drug Testing Programme, IOC Newsletter, July: 279

International Amateur Athletic Federation. (1928) Annual Meeting Minutes. Section 17, Report by Mr Genet of France. Appearance money. IOC Archives, 43. Lausanne: International Olympic Committee Library.

International Olympic Committee. (1968). $67^{\text {th }}$ Session Minutes, 7-11 October. Janofsky, M. (1991). Olympics: Coaches Concede That Steroids Fueled East Germany's Success in Swimming. New York Times.3 December.

Lausanne Declaration on Doping in Sport (1999). Adopted by the World Conference on Doping in Sport, February 4. https://wcd.coe.int/ViewDoc.jsp?id=402791. Accessed 3.11.15.

Møller, V. (2014). Who Guards the Guardians? The International Journal of the History of Sport. 31: 934-950. 
Møller, V., Waddington, I. and Hoberman, J. (eds) (2015). Routledge Handbook of Drugs and Sport. London and New York: Routledge

Killanin, M. (1983). My Olympic Years. London: Secker \& Warburg.

Pitsch, W. and Emrich, E. (2012). The frequency of doping in elite sport: Results of a replication study. International Review for the Sociology of Sport. 4: 559-580.

Porritt, A. (1965). Doping. Journal of Sports Medicine and Physical Fitness, 5: 166-168.

Pound, D. (2006). Inside Dope: How drugs are the biggest threat to sports, why you should care, and what can be done about them. Ontario: Wiley.

Prokop, L. (1966). The Problem of Doping. In K. Kato (ed) Proceedings of International Congress of Sports Sciences. The Japanese Union of Sport Sciences: Tokyo.

Ritchie, I. (2015). Understanding performance-enhancing substances and sanctions against their use from the perspective of history. In Møller, V., Waddington, I. and Hoberman, J. (eds) Routledge Handbook of Drugs and Sport. London and New York: Routledge.

Taylor, W. (1991). Macho Medicine: A History of the Anabolic Steroid Epidemic. North Carolina and London: McFarland \& Co., Jefferson

UK Anti-Doping (2015). Your Part in Clean Sport. http://www.ukad.org.uk/athletes/performancedevelopment/your-part/ Accessed 23.10. 2015

United States Anti-Doping Agency. (2015). Why Do You Compete Clean?. https://icompeteclean.usada.org/ Accessed 25.10.15

Venerando, A. (1964). Italian Experiments on the Pathology of Doping and Ways to Control It. Appendix to Council of Europe Committee for Out-of-School Education, Doping of Athletes: Reports of the Special Working Parties.Council of Europe: Strasbourg. 
World Anti-Doping Agency (2015a). WADA encourages Clean Sport community to Report Doping. https://www.wada-ama.org/en/media/news/2015-04/wada-encourages-clean-sport-community-toreport-doping Accessed 23.03.15

World Anti-Doping Agency (2015b) World Anti-Doping Code 2015, p.14 